-Supporting Information for-

\title{
Intramolecular Carbozincation of Unactivated Alkenes Occurs Through a Zinc Radical Transfer Mechanism
}

Theodore Cohen, ${ }^{\dagger *}$ Heather Gibney, ${ }^{\dagger}$ Roman Ivanov, ${ }^{\dagger}$ Edmund A.-H. Yeh, ${ }^{\dagger}$ Ilan Marek ${ }^{\dagger}$ and Dennis P. Curran *

Department of Chemistry, University of Pittsburgh, Pittsburgh, PA 15260, U. S. A., and the Mallat Family Laboratory of Organic Chemistry, Schulich Faculty of Chemistry, Institute of Catalysis Science and Technology and the Lise Meitner-Minerva Center for Computational Quantum Chemistry, Technion-Israel Institute of Technology, Technion City, Haifa 32000, Israel

\section{Table of Contents}

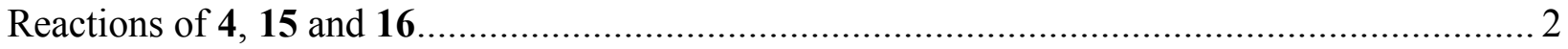

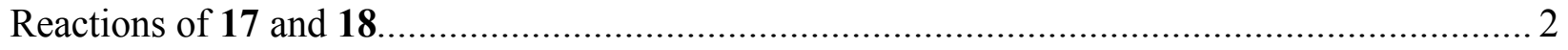

Experiments on the Oxygen Sensitivity of the Cyclization of the Alkenylzinc Derived from 1.... 3

\section{Reactions of 4, 15 and 16}

Full details for the atom transfer cyclizations of 4, 15 and 16, including temperature dependence plots, are in the MS Thesis of Heather Gibney, University of Pittsburgh, 2006. The thesis is permanently archived and openly available from the University of Pittsburgh Library Electronic Thesis Deposition (ETD) site at: http://etd.library.pitt.edu/ETD/available/etd-08042006-085451/

\section{Reactions of 17 and 18}

Compounds 17 and 18 were prepared as described by Marek and Normant. ${ }^{1}$

\section{GENERAL CYCLIZATION PROCEDURE}

To an NMR tube was added on $0.3 \mathrm{M}$ solution of iodo precursor (3-acetoxy-6-iodo-1hexene 17 or 6-iodo-3-pivaloxy-1-hexene 18) in benzene- $d_{6}$ and $10 \mathrm{~mol} \%$ bis(tributyltin). The resultant mixture was placed in a water bath 2 inches in front of a GE 275-W sunlamp. All experiments were done at room temperature $\left(25^{\circ} \mathrm{C}\right)$. The progress of the reaction and the isomer ratios of the products were monitored by recording ${ }^{1} \mathrm{H}$ NMR spectra of the reaction mixture and by gas chromatography (GC), Agilent MP-1 methyl siloxane capillary column (19091Z-413 E, $30 \mathrm{~m} \times 0.32$ ); temperature ramp: $+10{ }^{\circ} \mathrm{C} / \mathrm{min}$ from $40{ }^{\circ} \mathrm{C}-150{ }^{\circ} \mathrm{C}$, then hold $10 \mathrm{~min}$.

\footnotetext{
${ }^{\dagger}$ University of Pittsburgh

$\ddagger$ Technion-Israel Institute of Technology
} 


\section{Experiments on the Oxygen Sensitivity of the Cyclization of the Alkenylzinc Derived from 1}

General Description. Reactions were performed under a dry argon atmosphere in flame-dried glassware with magnetic stirring. Hexane was distilled from $\mathrm{CaH}_{2}$. Diethyl ether and THF were distilled from sodium/benzophenone under a dry argon atmosphere. Solvents were additionally degassed by ultrasonication for $30 \mathrm{~min}$ at ambient temperature in an argon atmosphere. Other starting chemicals were used from commercial sources without further purification or prepared and purified as described elsewhere.

Reike's zink. To a three-neck $100 \mathrm{~mL}$ round bottom flask, equipped with a magnetic stirrer, argon inlet and a rubber septum was added $20 \mathrm{~mL}$ of dry THF. Lithium ribbon was prepared by scraping the dark oxide coating off of the surface while it was immersed in fresh mineral oil. The shiny metal was dipped in dry hexane in order to remove the oil and then weighed (0.1414 g, $20.5 \mathrm{mmol})$ in a tared beaker containing mineral oil. The metal was sliced into small pieces while it was still immersed in mineral oil. The lithium pieces were dipped again in hexane prior to addition to the flask. Naphthalene $(2.90 \mathrm{~g}, 22.6 \mathrm{mmol})$ was then added quickly under increased argon flow. The reaction mixture was stirred at ambient temperature for $2 \mathrm{~h}$. A $0.5 \mathrm{M}$ THF solution of $\mathrm{ZnCl}_{2}(20.0 \mathrm{~mL}, 10 \mathrm{~mol})$ was added dropwise by using a syringe pump ( 1 drop per 2-3 sec). The suspension was stirred for $20 \mathrm{~min}$ at room temperature. The stirring was stopped and the zinc was allowed to settle. The supernatant was removed by syringe, dry oxygen free ether $(20 \mathrm{~mL})$ was added and the suspension was being stirred for $5 \mathrm{~min}$ and the zinc metal was allowed to settle. Then the supernatant was removed again by mean of a syringe. This washing process was repeated twice and finally dry oxygen free ether $(20 \mathrm{~mL})$ was added to the active zinc slurry, which was ready to use.

Oxygen-free zincation. A solution of 6-iodo-1-hexene 1 (1.46 g, $7.13 \mathrm{mmol})$ in $5 \mathrm{~mL}$ of dry oxygen free ether was added to a vigorously stirred suspension of the active zinc at ambient temperature. The reaction mixture was stirred for $24 \mathrm{~h}$ and then cooled with an ice-water bath and an excess of solid iodine $(3.4 \mathrm{~g}, 13.4 \mathrm{mmol})$ was added. After the mixture had been stirred for $20 \mathrm{~min}$ at room temperature, $100 \mathrm{~mL}$ of water and $50 \mathrm{~mL}$ of ether were added. The layers were separated and the aqueous one was extracted three times with ether. The combined extracts were washed with dilute $\mathrm{Na}_{2} \mathrm{~S}_{2} \mathrm{O}_{3}$, dried over $\mathrm{MgSO}_{4}$ and concentrated in vacuum to afford only starting 6-iodo-1-hexene 1 (1.24 g, 85\%) with no trace of cyclized product.

Carbozincation in the presence of air. A solution of 6-iodo-1-hexene $\mathbf{1}(1.37 \mathrm{~g}, 6.51$ $\mathrm{mmol}$ ) in $5 \mathrm{~mL}$ of dry oxygen free ether was added to a vigorously stirred suspension of the active zinc at ambient temperature. After $30 \mathrm{~min}$, the reaction mixture was transferred completely to another sealed $50 \mathrm{~mL}$ flask containing ambient atmosphere and then was stirred for $24 \mathrm{~h}$. The reaction mixture was cooled with an ice-water bath and an excess of solid iodine ( $3.8 \mathrm{~g}, 15.0 \mathrm{mmol}$ ) was added. After the mixture had been stirred for $20 \mathrm{~min}$ at room temperature, $100 \mathrm{~mL}$ of water and $50 \mathrm{~mL}$ of ether were added. The layers were separated and the aqueous one was extracted three times with ether. The combined extracts were washed with dilute $\mathrm{Na}_{2} \mathrm{~S}_{2} \mathrm{O}_{3}$, dried over $\mathrm{MgSO}_{4}$ and concentrated in vacuum to afford $1.1 \mathrm{~g}(81 \%)$ of (iodomethyl)cyclopentane $3(\mathrm{E}=\mathrm{I})^{2}$ as a crude product containing about $7 \%$ of the starting 6-iodo1-hexene 1. ${ }^{1} \mathrm{H}$ NMR $(300 \mathrm{MHz})$ in $\mathrm{CDCl}_{3} \delta 3.19\left(\mathrm{~d}, \mathrm{~J}=6.9 \mathrm{~Hz}, 2 \mathrm{H}, \mathrm{CH}_{2} \mathrm{I}\right), 2.22-2.12(\mathrm{~m}, 1 \mathrm{H}$, $\left.\mathrm{CHCH}_{2} \mathrm{I}\right), 1.89-1.80(\mathrm{~m}, 2 \mathrm{H}$, ring $\mathrm{H}), 1.71-1.58(\mathrm{~m}, 4 \mathrm{H}$, ring $\mathrm{H}), 1.28-1.20(\mathrm{~m}, 2 \mathrm{H}$, ring $\mathrm{H})$; ${ }^{13} \mathrm{C}$ NMR $(75 \mathrm{MHz})$ in $\mathrm{CDCl}_{3} \delta 42.60,33.34,25.46,14.16$. 
(Phenylthiomethyl)cyclopentane. A three-neck $50 \mathrm{~mL}$ flask equipped with a glass stopper, a rubber septum and a gas inlet was purged three times with argon and charged with 10 $\mathrm{mL}$ dry THF and thiophenol $(0.64 \mathrm{~mL}, 6.3 \mathrm{mmol})$. The flask was cooled with ice-water bath and a $1.7 \mathrm{M}$ solution of $t$-BuLi in pentane $(3.6 \mathrm{~mL}, 6.1 \mathrm{mmol})$ was added dropwise. The reaction mixture was stirred for $15 \mathrm{~min}$ at room temperature and a solution of freshly prepared crude (iodomethyl)cyclopentane 3 (E=I, $1.05 \mathrm{~g}, 5.0 \mathrm{mmol})$ in THF $(5 \mathrm{~mL})$ was added. After the solution had been stirred overnight at ambient temperature, the reaction mixture was poured into $100 \mathrm{~mL}$ of saturated aqueous $\mathrm{K}_{2} \mathrm{CO}_{3}$. The layers were separated and the aqueous one was extracted with ether. The combined organic layer was washed with dilute $\mathrm{Na}_{2} \mathrm{~S}_{2} \mathrm{O}_{3}$ and dried over $\mathrm{MgSO}_{4}$. Solvents were removed by rotary evaporation and flash chromatography $(2.5 \%$ EtOAc/hexanes) afforded $0.83 \mathrm{~g}(86 \%)$ of the titled product. ${ }^{3}{ }^{1} \mathrm{H} \mathrm{NMR}(300 \mathrm{MHz})$ in $\mathrm{CDCl}_{3} \delta$ $7.32-7.08$ (m, 5H, aromatic), $2.99\left(\mathrm{~d}, \mathrm{~J}=7.2 \mathrm{~Hz}, 2 \mathrm{H}, \mathrm{CH}_{2} \mathrm{~S}\right), 2.14-2.04\left(\mathrm{~m}, 1 \mathrm{H} \mathrm{CHCH}{ }_{2} \mathrm{~S}\right)$, $1.84-1.81(\mathrm{~m}, 2 \mathrm{H}$, ring $\mathrm{H}), 1.61-1.51(\mathrm{~m}, 4 \mathrm{H}$, ring $\mathrm{H}), 1.30-1.26(\mathrm{~m}, 2 \mathrm{H}$, ring $\mathrm{H}) ;{ }^{13} \mathrm{C} \mathrm{NMR}$ (75 MHz) in $\mathrm{CDCl}_{3} \delta 137.6,128.9,128.8,125.6,39.9,39.5,32.5,25.4$.

\footnotetext{
${ }^{1}$ Meyer, C.; Marek, I.; Courtemanche, G.; Normant, J.-F. Tetrhedron, 1994, 50, 11665-11692

${ }^{2}$ Bailey, W. F; Carson, M. W. J. Org. Chem. 1998, 63, 361-365.

${ }^{3}$ Russell, G. A.; Ngoviwatchai, P.; Tashtoush, H. I.; Pla-Dalmau, A.; Khanna R. K. J. Am. Chem. Soc. 1988, 110, 3530-3538.
} 